\title{
Las raíces kantianas de la autonomía personal en el pensamiento de Rawls
}

\author{
The Kantian Roots of personal autonomy in the thought of Rawls
}

\author{
Jorge CREgo \\ Universidad Internacional de La Rioja \\ https://orcid.org/0000-0001-7072-6569 \\ jorge.crego@unir.net
}

RECIBIDO: 20/12/2019 / ACEPTADO: 19/01/2020

\begin{abstract}
Resumen: Rawls reconoce la analogía entre su concepción de la personalidad moral y el pensamiento de Kant. Sin embargo, numerosos filósofos han discutido dicha similitud. El presente artículo tiene como objeto evaluar el fundamento kantiano de la libertad en Rawls, específicamente bajo la idea de la autonomía personal. Se concluye que una determinada interpretación de Kant, que incorpore sus reflexiones tanto sobre la ley moral como sobre la felicidad como fin intrínseco del ser humano, permite señalar dicha analogía y comprender mejor la idea rawlsiana de libertad.
\end{abstract}

Palabras clave: libertad, justicia, contrato social, felicidad, personalidad moral.

\begin{abstract}
Rawls acknowledges the analogy between his conception of the moral personality and the thought of Kant. However, many philosophers have discussed that similarity. This article aims to evaluate the Kantian foundation of Rawlsian liberty. Specifically, it assesses the idea of personal autonomy. The conclusion is that certain interpretation of Kant, which incorporates both his thinkings on the moral law and on happiness as an intrinsic purpose of the human being, allows the acknowledgement of the aforementioned analogy, and thus enables a better understanding of the Rawlsian idea of freedom.
\end{abstract}

Keywords: freedom, liberty, justice, social contract, happiness, moral personality.

Sumario: 1. INTRODUCCIÓN. 2. EL PROBLEMA DE LA INTERACCIÓN ENTRE DEONTOLOGÍA Y AUTONOMÍA PERSONAL. 3. LOS MÁRGENES DE AUTONOMÍA PERSONAL DEL SER NOUMÉNICO. 3.1. La hipótesis de la autonomía personal en la elección del modo de ejecución de los deberes imperfectos. 3.2. La elección personal autónoma sobre las «verdaderas necesidades». 4. UNA LECTURA RAWLSIANA DE LAAUTONOMÍA PERSONAL EN KANT. 5. CONCLUSIÓN. 6. BIBLIOGRAFÍA.

\section{INTRODUCCIÓN}

$\mathrm{D}$ esde la publicación de $A$ Theory of fustice, numerosos intérpretes han evaluado la conexión entre la propuesta filosófica de Rawls y las ideas de Kant. En dicha obra, Rawls defiende la posibilidad de una «interpretación kantiana de la justice as fairness $»^{1}$. La bibliografía dedicada a esta interpreta-

1 RaWls, J., Teoría de la justicia, traducción de González, M.D., 2 ${ }^{\mathrm{a}}$ ed., Fondo de Cultura Económica, México, 1995, pp. 236 y ss. Se ha optado por no traducir justice as fairness por mantener la idea original de Rawls sin prejuzgar qué término español habría que emplear como sinónimo de fairness tal como entiende Rawls esta última. La influencia de Kant en obras posteriores de Rawls es meridiana. Basta con comprobar simplemente los títulos de trabajos como A Kantian 
ción ha indagado sobre diversos modos de comprender la relación entre Rawls y Kant, centrándose en diferentes elementos de las teorías defendidas por ambos autores y dando como resultado interpretaciones divergentes de Rawls.

Algunos autores se han ocupado de desvelar la relación entre Kant y Rawls desde perspectivas como la comparación del carácter constructivista de sus teorías ${ }^{2}$, o el modo en que las ideas de Kant pueden apoyar una defensa de los dos principios rawlsianos de la justicia ${ }^{3}$. Uno de los enfoques ha sido la comparación de la concepción de la persona moral sostenida por Rawls y la del ser racional finito defendida por Kant. El presente trabajo tiene por objeto profundizar en la consideración de la relación entre ambas concepciones de la personalidad moral, específicamente en lo que se refiere a la idea de libertad y la comprensión de la autonomía personal.

La relevancia de la influencia de Kant en Rawls es más acusada precisamente en su idea de la persona moral libre e igual. El propio filósofo estadounidense pone de manifiesto que «es un error [...] acentuar el lugar que la generalidad y la universalidad ocupan en la ética kantiana» ${ }^{4}$. Según él, la interpretación kantiana de la justice as fairness hunde sus raíces en «la noción kantiana de autonomía» ${ }^{5}$, y la posición original es «el punto de vista a través del cual seres noumenales contemplan el mundo ${ }^{6}$. La idea de autonomía kantiana es, para Rawls, una influencia esencial en su pensamiento ${ }^{7}$.

Conception of Equality y Kantian Constructivism in Moral Theory. Podría considerarse que en el liberalismo político desarrollado con posterioridad a las obras más «kantianas» la relación entre su propuesta y las ideas de Kant desaparecen. Sin embargo, de la cita de las diferentes obras del liberalismo político que se harán en este trabajo se puede extraer la conclusión contraria.

2 Este es el objeto principal de análisis de Krasnoff; cfr. KraSNOFF, L., «How Kantian is Constructivism?», Kant-Studien, v. 90, n. 4, 1999, pp. 385-409; KRASNOFF, L., «Kantian Constructivism», en MANDle, J.; ReIDY, D.A. (eds.), A Companion to Rawls, Wiley Blackwell, Malden, 2014, pp. 73-87.

3 GuYer, P., Kant on Freedom, Law, and Happiness, Cambridge University Press, Cambridge, 2000, pp. 262 y ss.

4 RAWLS, Teoría de la justicia, op. cit., p. 236. Para una interpretación fundamentada en la relevancia del principio formal de la universalidad, cfr. BudDE, K., «Rawls on Kant: Is Rawls a Kantian or Kant a Rawlsian?», European fournal of Political Theory, v. 6, n. 3, 2007, pp. 339-358.

5 Todo ello pese a que sea cierto que Rawls emplee términos con una proyección mayor, como el de «imperativo categórico», o se refiera a la naturaleza contractual de la teoría de Kant. Esto es así porque pese a su uso, este siempre se lleva a cabo para sostener su premisa esencial, que es la de la analogía entre la persona moral rawlsiana y la desarrollada por Kant; RAWLS, Teoría de la justicia, op. cit., pp. 24, 238.

6 Ibid., p. 240.

7 «o que distingue la forma kantiana del constructivismo es esencialmente esto: especifica una concepción particular de la persona como un elemento en un procedimiento de construcción 
Rawls reconoce que en otros aspectos difiere de las ideas de Kant. En primer lugar, su teoría se dirige a desentrañar los principios de la justicia en la estructura básica de la sociedad, no un código moral para la conducta de los individuos $^{8}$. Además, inserta las ideas kantianas «dentro del sistema de una teoría empírica» ${ }^{9}$. Por último, el problema que enfrenta Rawls tiene un objeto más restringido. No se trata de adentrarse en las complejidades filosóficas de la naturaleza de la libertad y del modo en que las personas morales pueden evitar la heterodeterminación, sino simplemente de proyectar una estructura social en la que las personas morales puedan actuar sin verse sometidas a una coerción humana o social y se desarrolle un marco de justicia que les permita sustraerse a dichas constricciones ${ }^{10}$.

Como se intentará demostrar, las aparentes diferencias entre las dos concepciones en lo relativo a la autonomía personal se pueden resolver a través de una interpretación de la concepción del ser racional finito que permite el ejercicio de un importante grado de autonomía personal. Esto aproxima las teorías de ambos autores y permite que, a través de la consideración de los rasgos en común de ambas, se adquiera una mejor comprensión de la propuesta de Rawls.

razonable»; Rawls, J., «Kantian Constructivism in Moral Theory», Collected Papers, Harvard University Press, Cambridge, 1999, pp. 303-358., p. 304. Las citas futuras de obras recogidas en los Collected Papers se referirán siempre a la paginación de dicha compilación.

8 RaWls, Teoría de la justicia, op. cit., p. 237.

9 RaWLs, Teoría de la justicia, op. cit., p. 241. Como afirma el propio autor, «Kant pudo haber querido decir que su teoría se aplicaba a todos los seres racionales, como tales, y que, por tanto, la situación social del humano en el mundo parece no tener posibilidad alguna de determinar los principios fundamentales de la justicia. De ser así, he aquí otra diferencia entre la teoría de Kant y la justicia como imparcialidad». En un sentido similar, RAWLS, J., «A Kantian Conception of Equality», Collected Papers, op. cit., p. 264. Algunos autores afirman que esto no es contradictorio con las tareas desarrolladas por Kant a nivel teórico; cfr. DARWALL, S.L., «Is There a Kantian foundation for Rawlsian Justice?», en Blocker, G.; Smith, E. (eds.), Fobn Rawls' Theory of Social Fustice, op cit., pp. 311-345; HöFFE, O., «Is Rawls' Theory of Justice Really Kantian?», Ratio Bristol, v. 26, n. 2, 1984, p. 199; Herman, B., «Mutual Aid and Respect for Persons», Ethics, v. 94, n. 4, 1984, p. 141.

10 Cfr., por ejemplo, TAYLOR, R.S., Reconstructing Rawls. The Kantian Foundations of Justice as Fairness, Pennsylvania State Press, Pennsylvania, 2011, p. 6. Una idea similar se desprende de todo el análisis de la relación entre Rawls y Kant en Guyer; cfr. GuYER, Kant on Freedom, Law, and Happiness, op. cit., pp. 236 y ss. Höffe, por su parte, afirma que la libertad que pretende asegurar Rawls se refiere a las acciones, no a la voluntad (will). Este autor, sin embargo, ofrece una serie de consideraciones que, según él, demuestran que en Rawls, la esfera jurídico-política, la esfera moral, y la esfera económica, confluyen de una forma en cierto modo poco refinada; cfr. HöFFE, «Is Rawls' Theory of Justice Really Kantian?», op. cit., p. 113. 
Este trabajo no puede abordar la ardua tarea de ofrecer una interpretación completa de la obra de Kant, intentando desentrañar su significado original ${ }^{11}$. Para el objetivo propuesto, basta con determinar si en la obra de Rawls se puede encontrar una forma de caracterizar a la persona moral que pueda hundir sus raíces en alguno de los modos en que se ha interpretado a Kant. Con ello se podría considerar que existe alguna influencia de Kant en Rawls, y serviría para comprender mejor su interrelación y la naturaleza de la propuesta de la persona moral libre e igual de la justice as fairness ${ }^{12}$.

Sin embargo, resulta pertinente iniciar la indagación con una consideración clara de las limitaciones de la similitud entre las teorías de ambos autores. Rawls afirma de forma tajante que su propuesta es «análoga, no idéntica» a la del filósofo prusiano ${ }^{13}$. Aquí se pretenden explorar las analogías existentes en la concepción de la persona moral. Como se intentará demostrar, se pueden identificar tres analogías relevantes: las similitudes entre (i) la interacción entre felicidad y moral en Kant y racionalidad y razonabilidad (o bondad y justicia) en Rawls, entre (ii) la autonomía personal reconocida por Kant según algunas interpretaciones de su obra y la facultad moral para una concepción del bien de Rawls, y (iii) la relevancia de la prioridad de lo justo sobre lo bueno en ambos autores.

Para llevar a cabo el estudio propuesto, el trabajo se estructura del siguiente modo. En primer lugar, se presentan aisladamente algunos pasajes de la interpretación kantiana desarrollada por Rawls, que tomados de este modo reflejan una concepción unilateralmente nouménica. Se señala entonces el

11 La disputa existente en el seno de los intérpretes de Kant es tan relevante que, de hecho, podría decirse sin temor que muchas páginas dedicadas a estudiar la relación de Rawls con Kant son realmente revisiones del debate sobre cómo ha de entenderse a Kant; cfr. por ejemplo, TAYLOR, Reconstructing Rawls, op. cit., p. 37, sobre la acusación de heteronomía hecha a Rawls por referirse a la voluntad de las personas morales de «asegurar su concepción del bien»; BUDDE, «Rawls on Kant», op. cit., passim, que achaca la identificación de Kant y Rawls a errores de mala interpretación de la teoría kantiana; KRASNOFF, «How Kantian is Constructivism?», op. cit., passim; KRASNOFF, «Kantian Constructivism», op. cit., passim, en donde critica determinado modo de interpretar el constructivismo de Kant.

12 En cierto modo, Rawls ya reconoce que este es el objetivo de la «interpretación kantiana de la justice as fairness»: «la interpretación kantiana no tiene por objeto ser una interpretación de la doctrina real de Kant, sino más bien, de la justice as fairness»; RAWLS, Teoría de la justicia, op. cit., p. 241.

13 RaWLs, J., «Justice as Fairness: Political not Metaphysical», Collected Papers, op. cit., p. 389, nota 2.; en un sentido similar, RAWLs, Teoría de la justicia, op. cit., p. 236 y ss., que afirma que la justice as fairness permite una «interpretación kantiana»; Rawls, «Kantian Constructivism in Moral Theory», op. cit., p. 303, donde se habla de «raíces kantianas». 
modo en que dicha interpretación se aviene mal con el importante rol que Rawls otorga a la autonomía personal, a través de la facultad moral para una concepción del bien que caracteriza su concepción de la libertad. Una vez identificada la presumible paradoja existente entre la autonomía kantiana y la autonomía personal, se exponen las críticas que ha recibido Rawls por parte de defensores de un kantismo ajeno a la idea de autonomía personal.

El tercer apartado se dedica a presentar dos intentos de conciliación de ambas ideas de autonomía en el pensamiento de Kant a partir de la noción de los deberes imperfectos de la virtud. Una primera propuesta, defendida por Taylor, señala que el sujeto puede elegir el tipo de actividades a través de las cuales cumple dicho deber, limitándose la autonomía personal a dicha decisión de tipo modal. Por otro lado, Budde evalúa la idea de las «verdaderas necesidades» para señalar que el ser racional finito decide con autonomía personal qué grado de sacrificio de la felicidad propia se debe en pro de la promoción de la felicidad ajena.

En el cuarto apartado se presenta una interpretación que, partiendo de la idea de felicidad kantiana, expande la idea de autonomía personal más allá de los deberes imperfectos. Frente a las concepciones precedentes, unilateralmente nouménicas, esta considera al ser racional finito en toda su complejidad, evaluando el modo en que su carácter dual, fenoménico y nouménico, permite la apertura de un campo de autonomía personal similar al propuesto por Rawls.

Tras esto, se concluye exponiendo las similitudes entre esta última interpretación del pensamiento de Kant y la propuesta de Rawls. Se señala no solamente el modo de articular la autonomía personal con la autonomía moral kantiana, sino también cómo la articulación entre felicidad y moral en el pensamiento de Kant así entendido permite reconocer la influencia del pensamiento kantiano en un elemento central de la justice as fairness de Rawls: la prioridad de lo justo sobre lo bueno.

\section{El PROBLEMA DE LA INTERACCIÓN ENTRE DEONTOLOGÍA Y AUTONOMÍA PERSONAL}

Existen una serie de pasajes de la obra de Rawls que se orientan hacia una interpretación kantiana de su idea de libertad. En ocasiones, el filósofo estadounidense recurre a Kant para caracterizar a las personas morales de un modo preponderantemente nouménico, similar a la interpretación tradicio- 
nal de la idea kantiana de autonomía. En el apartado de $A$ Theory of Justice dedicado a la interpretación kantiana de su propuesta sobre la justicia, Rawls adopta la idea kantiana de que «una persona actúa autónomamente cuando los principios de su acción son elegidos por ella como la expresión más adecuada de su naturaleza como ser libre y racional», de modo que dichos principios «no se adoptan a causa de su posición social o sus dotes naturales, o a la vista de la sociedad específica en la que vive o de las cosas que desea» ${ }^{14}$. Por otro lado, Rawls afirma que es el sentido de la justicia el que permite mantenernos en el «reino de la libertad», evitando abrir la puerta «a las contingencias y a los accidentes del mundo ${ }^{15}$. En obras posteriores, analizando la influencia kantiana en su pensamiento, Rawls afirma que «las personas no consideran sus deseos como determinados por acontecimientos más allá de su control» ${ }^{16}$. Precisamente por esto, el velo de la ignorancia característico de la posición original, su interpretación predilecta del contrato social, oculta información de modo que se pueda construir un contexto de autonomía en sentido kantiano, que permite «actuar independientemente de la determinación de causas ajenas» ${ }^{17}$. Este velo refleja los efectos de la autonomía kantiana, reforzando entonces la idea de que para Kant, la libertad exige la ausencia de causas ajenas que determinen la acción humana ${ }^{18}$. En palabras de Taylor, la autonomía moral kantiana impone una ley moral que no solamente se refiere a cuestiones de derecho, sino que también establece la necesidad de adoptar una serie de fines particulares ${ }^{19}$.

Pese a la rotundidad de estas afirmaciones, el pensamiento de Rawls se caracteriza por otorgar un papel preponderante a los deseos de los individuos, incluso si estos han sido determinados por elementos contingentes. Por ejem-

14 RaWls, Teoría de la justicia, op. cit., p. 237. En la p. 236 se usa la expresión «libertad de la contingencia y de la casualidad». Las frases referidas producen una confusión relevante. No parece claro qué ha de entenderse por «principio de su acción», o bien máximas o bien leyes morales, que en la teoría rawlsiana se deberían sustituir por los principios de la justicia. Esto es fundamental, porque dicha diferencia, que se tratará más adelante, afecta al modo de entender la teoría de Kant y Rawls.

15 Ibid., p. 519.

16 RAWLS, «A Kantian Conception of Equality», op. cit., p. 261.

17 Ibid., p. 265.

18 Efectivamente, esta es la definición que Kant da de la «libertad negativa»; cfr. KaNT, I., Fundamentación para una metafísica de las costumbres, traducción de ARAMAYO, R., Alianza, Madrid, 2002, Ak. IV 446: «libertad sería la propiedad de [la voluntad] para poder ser eficiente independientemente de causas ajenas que la determinen»; énfasis en el original.

19 TAYLOR, Reconstructing Rawls, op. cit., p. 74. 
plo, afirma que «[n]o hay objeción alguna a hacer al ajuste de los proyectos racionales a estas contingencias [las facultades, aspiraciones, circunstancias especiales, la posición social y las dotes naturales], porque los principios de la justicia han sido elegidos ya y determinan el contenido de estos proyectos, los objetivos que fomentan y los medios de que se valen $»^{20}$.

Frente a una concepción determinista de la autonomía, en que las leyes morales determinan el contenido de la acción humana, Rawls reconoce la existencia de un espacio de autonomía personal en que el sujeto puede elegir por sí mismo cuál es su concepción de lo bueno. La idea de libertad de Rawls se caracteriza por la facultad moral de los sujetos para «formar, revisar y perseguir racionalmente una concepción del bien», convirtiendo su deseo en su propio bien, siempre y cuando este respete las restricciones que imponen los principios de la justicia ${ }^{21}$.

¿Cómo se puede afirmar que las personas están sometidas a principios morales que determinan su acción pero, a la vez, gozan de una autonomía personal que les permite elegir su modo de vida? Taylor plantea la paradoja de la autonomía personal en la obra de Kant del siguiente modo ${ }^{22}$ :

«[U]na autonomía personal verdaderamente kantiana [...] tendría que satisfacer dos criterios aparentemente inconsistentes:

1. Necesitaría estar motivada en el fondo no por intereses idiosincráticos y pasiones, sino por la razón pura práctica, esto es, motivada por razones objetivas, que son universales en la forma, obligan a todos los seres racionales finitos, y otorgan una «unidad a nuestras vidas» que podría faltar bajo el mero imperio de la naturaleza y la cultura;

2. Necesitaría hacer espacio sustancial a las razones subjetivas (i. e., razones específicas de agentes particulares) para hacer de la auto-creación o

20 RaWLs, Teoría de la justicia, op. cit., pp. 407, 511.

21 Rawls, J., El liberalismo político, traducción de DomÈnech, A., Crítica, Barcelona, 1996, pp. 59-65, 106. Por ejemplo, Sandel, Buchanan o Doppelt han interpretado a Rawls en este sentido, enfatizando la autonomía personal que otorga a los individuos; cfr. SANDEL, M.J., Liberalism and the Limits of fustice, $2^{\mathrm{a}}$ ed., Cambridge University Press, Cambridge, 1998, p. 154; Buchanan, A., Marx and Justice: The Radical Critique of Liberalism, Methuen, Londres, 1982, pp. 138 y ss.; DoppelT, G., «Is Rawls's Kantian Liberalism Coherent and Defensible?», Ethics, v. 99, n. 4, 1989, pp. 815-851. Las interpretaciones de Buchanan y Doppelt son especialmente relevantes, puesto que se refieren específicamente a la ascendencia kantiana de la propuesta de Rawls.

22 Esta idea de autonomía personal debe identificarse con la facultad moral para una concepción del bien referida por Rawls, como se verá seguidamente. 
la auto-autoría una posibilidad real, puesto que la autonomía en el modelo kantiano amenaza con reducir la '[auto-]autoría... a un punto vacío, al permitir sólo un grupo de principios que la gente pueda legislar racionalmente, y son los mismos para todos'» ${ }^{23}$.

Esta paradoja, a priori, parece exigir la negación de uno de los dos elementos formulados. El problema de fondo, como se tratará de demostrar, es el modo de articular dos elementos que ambos autores consideran consustanciales a la naturaleza humana: la moral y la felicidad, en términos kantianos; o lo justo y lo bueno, en términos rawlsianos.

La solución más implausible, dado el rechazo de ambos autores de concepciones que den pie al desarrollo irrestricto de los deseos de los sujetos, es la de negar el primer elemento de esa paradoja. Las críticas de Rawls al utilitarismo se dirigen precisamente a negar la justicia de un paradigma que descuide la ponderación de elementos ajenos al propio deseo de los sujetos. Guyer identifica en la obra de Kant esta doctrina como el riesgo de «sustituir el imperativo del deber por el imperativo de buscar nuestra propia felicidad $\gg^{24}$. Dicho autor afirma que Kant dedica la Sección II de la Fundamentación a resolver este riesgo ${ }^{25}$. Parece bastante claro que la obra de Kant no permite una lectura que otorgue a la felicidad, a la persecución de fines sustentados en razones subjetivas, una predominancia irrestricta basada en la capacidad para perseguir libremente la concepción propia del bien formulada por el sujeto. Por eso mismo, no resulta necesario argumentar cómo sería resueltamente anti-kantiano resolver la paradoja negando el primer elemento, el de las razones objetivas.

Levine ofrece una lectura de Kant en la que se niega la autonomía personal, el segundo elemento de la paradoja. Este autor afirma que «la posición de Kant descansa en la tesis de que la razón práctica pura proporciona fines para seres razonables independientemente de cualquier circunstancia no-racional o extra-racional», de modo que «un ser razonable será impulsado por 'incentivos subjetivos', por deseos, pero sólo en la medida en que sean derivados de la propia razón ${ }^{26}$.

23 TAYLOR, Reconstructing Rawls, op. cit., pp. 75-76. La cita es de Raz; cfr. RAZ, J., The Morality of Freedom, Clarendon Press, Oxford, 1986, p. 370, nota 2.

24 GUYER, Kant on Freedom, Law, and Happiness, op. cit., p. 212.

$25 \mathrm{Ibid}$.

26 LeVINE, A., «Rawls' Kantianism», Social Theory and Practice, v. 3, n. 1, 1974, p. 52. 
Budde también desarrolla una interpretación similar, en la que el propio imperativo categórico y su requisito formal de universalidad «proporcionan» el contenido de la ley moral ${ }^{27}$, y por lo tanto determinan el modo de conducta de las personas morales. Es decir, la razón pura práctica determina los fines de la acción de los seres racionales finitos. Como ella misma afirma, no existe espacio para la «noción ordinaria de libertad (de elección)» si aquello que debemos hacer está determinado a priori y por la mera forma. En este sentido, Budde es tajante al afirmar que «[p]ara Kant, que el imperativo categórico pueda determinar máximas y acciones por su mera forma [...] es exactamente la fortaleza de la ley moral $\gg^{28}$.

Esta autora señala cuál es el motivo por el que Rawls echa mano de la autonomía personal, un elemento que, para ella, es ajeno a la teoría kantiana. Como ya se ha apuntado, Rawls señala que los elementos formales del deber moral expuestos por Kant tienen un papel reducido ${ }^{29}$. Precisamente la escasa confianza en dichos elementos es la que le lleva a incluir la idea de «libertad de elección» para poder identificar el contenido de las conductas debidas. Sin embargo, si se reconoce la suficiencia de los rasgos formales del deber moral para establecer el contenido de los fines debidos por los individuos, no resulta necesaria la autonomía personal para llevar a cabo dicha función de concreción. Budde habla de que para Rawls es preciso «dar 'contenido' a la voluntad del sujeto ${ }^{30}$, por entender precisamente que el imperativo categórico no lo da.

En el pensamiento de Budde se puede observar cuál es la interpretación de Kant que permite expurgar la autonomía personal de su teoría. Una consideración formalista de la moral kantiana, en la que la universalidad exigida por el imperativo categórico es capaz de proporcionar el contenido de los fines debidos de la acción de los seres racionales, no requiere de un mecanismo adicional (la autonomía personal) para identificar dicho contenido. Si se asume esta interpretación de Kant, difícilmente se puede concebir la propuesta de Rawls como análoga, dada la centralidad de la autonomía personal en la concepción de los sujetos de la justice as fairness.

27 BudDE, «Rawls on Kant», op. cit., pp. 352 y ss. El término «proporcionar» [provide] es utilizado por Levine, que sostiene una posición similar a la de Budde; cfr. LEVINE, «Rawls' Kantianism», op. cit., p. 52.

28 BUDDE, «Rawls on Kant», op. cit., pp. 352-353.

29 RAWLS, Teoría de la justicia, op. cit., p. 236.

30 BUDDE, «Rawls on Kant», op. cit., p. 352. 


\section{LOS MÁRGENES DE AUTONOMÍA PERSONAL DEL SER NOUMÉNICO}

Existen otras interpretaciones que reconocen un espacio, siquiera limitado, a la autonomía personal. En este caso, se abre una posibilidad de conciliar los dos elementos de la presunta paradoja antes expuesta. Se reconoce así la posibilidad de tener en consideración las «razones específicas de agentes particulares» en lo referente a la determinación de su propia felicidad, o de sus concepciones del bien o planes de vida.

Raz señala que las interpretaciones expuestas en el anterior apartado terminan por configurar una concepción un tanto paradójica de la libertad. Si la libertad es asumir como propio un fin impuesto por la forma de la ley moral, se pierde un elemento importante. La autonomía personal queda reducida a la nada por una concepción kantiana de este tipo ${ }^{31}$. En este modo de interpretar a Kant, la paradoja se resolvería negando el segundo elemento de la misma, es decir, rechazando la existencia de un espacio válido para las razones subjetivas en la acción de las personas morales como seres racionales finitos. Los principios morales se encargarían de determinar fines a la conducta humana. Para Guyer, Kant intenta eludir esta lectura en la Sección III de la Fundamentación, reconociendo en su teoría la existencia de una esfera de autoautentificación en la que quepa la elección de los fines del sujeto ${ }^{32}$. Esta interpretación podría acercar el pensamiento de Kant a la propuesta de Rawls en lo relativo a la facultad moral para una concepción del bien.

En este apartado se expondrán dos interpretaciones del surgimiento de la autonomía personal en Kant centrados en la idea de los deberes imperfectos de la virtud. El objetivo es señalar cómo esta vía de incorporación de la autonomía personal descansa en premisas que requieren una revisión completa de la interpretación expuesta en el anterior apartado.

\subsection{La bipótesis de la autonomía personal en la elección del modo de ejecución de los deberes imperfectos}

Para resolver la paradoja por él expuesta, Taylor elabora una «concepción kantiana extendida de la persona», relacionando tres formas de entender la autonomía: la autonomía moral (fuente de lo justo o lo correcto), la autonomía

31 RaZ, The Morality of Freedom, op. cit., p. 370.

32 GUYER, Kant on Freedom, Law, and Happiness, op. cit., p. 213. 
personal (fuente de la autoautentificación del bien) y la autorrealización ${ }^{33}$. La autonomía moral kantiana se define como la capacidad de la voluntad para limitar nuestro interés propio y actuar con capacidad autolegislativa, independientemente de «objetos de volición»y otras «causas ajenas» ${ }^{34}$. Rawls emplea esta idea para referirse al modo de actuar de las partes de la posición original, y por tanto se asume como rasgo de la persona moral, rasgo que en El liberalismo político se denomina «autonomía plena», aunque tenga ahí un alcance únicamente político, y no metafísico ${ }^{35}$. La autonomía personal se asocia con la facultad moral para una concepción del bien, tal como la formula Rawls; es la capacidad para crear un plan de vida individual y una concepción del bien ${ }^{36}$. La autorrealización se refiere, en palabras de Raz, al «desarrollo en toda su amplitud de todas, o todas las capacidades valiosas que posee una persona $\gg^{37}$.

Taylor propone una unificación jerarquizada de los tres elementos, en los que los superiores restringen y guían los inferiores y estos últimos, a su vez, sirven como instrumento o incluso parte constitutiva de los superiores ${ }^{38}$. Para los propósitos actuales, cabe dejar de lado la «autorrealización» y centrarse en la relación entre «autonomía moral» $\mathrm{y}$ «autonomía personal». En este contexto, Taylor ofrece una respuesta a la paradoja de entender que la «autonomía personal» debe ser motivada por la razón práctica pura, por razones objetivas, y a la vez dejar lugar a las razones subjetivas para permitir la autocreación y la autoautoría. Esto es así porque existe un ámbito en el que cabe esa «autonomía personal», esas razones subjetivas, pese a que las máximas de conducta deban respetar la ley moral. Taylor identifica ese campo con los «deberes imperfectos de la virtud hacia uno mismo y hacia otros» ${ }^{39}$. De este modo, en el terreno de los deberes imperfectos de la virtud, cabe la posibilidad de desarrollar un grado de subjetividad, decidiendo en qué modo se cumplen dichos deberes.

Su reconocimiento de un espacio de «autoautentificación» es muy restringido. Dicho autor parte de la distinción entre deberes de virtud perfectos e imperfectos. Los primeros exigen una determinada forma de conducta, activa

33 TAYLOR, Reconstructing Rawls, op. cit., pp. 72 y ss.

34 Ibid., pp. 62 y ss.

35 RAWLs, El liberalismo político, op. cit., pp. 108 y ss.

36 TAYLOR, Reconstructing Rawls, op. cit., pp. 66 y ss.

37 Ibid., pp. 69, 84; RAZ, The Morality of Freedom, op. cit., p. 375.

38 TAYLOR, Reconstructing Rawls, op. cit., p. 74.

39 Ibid., p. 80. Estos deberes morales imperfectos son «aquellos que permiten flexibilidad en la elección de acciones/omisiones siempre que el fin se siga adoptando»; cfr. ibid., p. 76. 
u omisiva, debido a que están lo suficientemente relacionados a un determinado fin como para que este los especifique. Sin embargo, los deberes imperfectos permiten diversos modos de cumplimiento, siempre y cuando el fin concreto sea aplicado ${ }^{40}$. Estos deberes imperfectos se refieren, en primer lugar, a uno mismo, exigiendo tanto la perfección natural (el cultivo de las facultades naturales y talentos del cuerpo, mente y espíritu) como la perfección moral (la educación de la disposición moral de uno mismo) ${ }^{41}$. Existen también deberes imperfectos hacia terceros: la beneficencia, la simpatía y la gratitud.

Como reconoce Taylor, Kant otorga un amplio espectro de opciones a la hora de determinar en qué modo desarrollar los diferentes talentos personales, así como el modo en que se ha de desarrollar la disposición moral, aunque en este caso la discreción es menor ${ }^{42}$. Taylor emplea entonces el ejemplo de la perfección personal para demostrar que no existe incompatibilidad entre cumplir con la razón objetiva y el imperativo categórico de la perfección natural y elegir desarrollar esa perfección a través de la realización de diferentes ocupaciones o, en sentido rawlsiano, planes de vida a los que cada individuo se sienta impulsado a adherirse como su propia concepción de la felicidad.

El caso de los deberes imperfectos para con otros es especialmente claro y, además, refleja una particularidad que servirá para establecer el punto de fuga hacia otro modo de concebir la aparición del campo de la autonomía personal de Kant que quizá se aproxime más a la idea de Rawls.

Taylor analiza la beneficencia, y cómo entra en juego la idea de felicidad en la determinación del modo en que se ha de cumplir con dicho deber imperfecto por parte de cada individuo. Este deber exige promover la felicidad de otros, «cuyo fin (permitido) hago yo con ello también mío» ${ }^{43}$. En este sentido, existen razones objetivas que exigen el cumplimiento del deber de beneficencia. Se trata de un imperativo categórico, independiente de cualquier inclinación, que deriva del respeto a la humanidad como fin en sí mismo. Pero además, según Taylor, también existe un espacio para la autonomía personal, para la autoautentificación de un determinado modo de ejercer la beneficencia

40 Ibid., p. 76.

41 Ibid., pp. 77-78. En algunos pasajes, Taylor niega que el deber moral imperfecto de la perfección moral deje espacio a la autonomía personal; ibid., p. 79.

42 Ibid.; Kant, I., La metafísica de las costumbres, traducción de Cortina OrTs, A.; Conill SANCHO, J., Tecnos, Madrid, 1989, Ak VI: 392.

43 TAYLOR, Reconstructing Rawls, op. cit., p. 78; KANT, La metafísica de las costumbres, op. cit., Ak VI: 388. 
en el que entran en juego las inclinaciones del sujeto (en el seno de la familia o las amistades, a través de la caridad, el voluntariado... $)^{44}$.

Por lo tanto, para Taylor, Kant permite la «autonomía personal» porque la autonomía moral guía a la autonomía personal (resolviendo el problema de la motivación por la razón práctica pura) a través de los deberes morales imperfectos, pero de una «forma inespecífica», dando lugar a la autocreación $o$, en cierto modo, a la «autoautentificación ${ }^{45}$. Es importante tener en cuenta que el espacio de autonomía personal es muy reducido: solamente existe en la elección del modo de desarrollar los talentos personales y en el modo de cumplir con los deberes frente a terceros.

\subsection{La elección personal autónoma sobre las «verdaderas necesidades»}

Kerstin Budde reconoce un espacio de indeterminación de los deberes morales en los deberes imperfectos hacia terceros similar al expuesto por Taylor. Sin embargo, su modo de concebirlo difiere de la autonomía «modal», y señala una idea esencial para comprender la extensión real de la autonomía personal en Kant. Pese a su concepción de la teoría del filósofo prusiano, justifica la flexibilidad de ejercicio de la beneficencia por motivos referidos a la interacción de dos seres racionales finitos con concepciones contrapuestas de la felicidad, en lugar de referirse al tipo de acción u omisión desarrollada, como hace Taylor. La cuestión aquí se plantea en términos cuantitativos, y no cualitativos, pero a su vez otorga una centralidad mayor a la idea de autoautentificación de los planes de vida y la idea de felicidad. Budde evalúa la interpretación rawlsiana de las «verdaderas necesidades humanas». En el marco de dicha evaluación recoge una referencia de Rawls a la Metafísica de las costumbres en la que se refleja la naturaleza de las «verdaderas necesidades»:

yo debo sacrificar a otros una parte de mi bienestar sin esperar recompensa, porque es un deber, y en tal caso es imposible señalar límites precisos: hasta dónde se puede llegar en el sacrificio. Depende en gran medida de qué sea para cada uno verdadera necesidad, según su modo de sentir, habiendo de confiarse a cada cual que lo determine él mismo. Porque favorecer la feli-

44 TAYLOR, Reconstructing Rawls, op. cit., p. 79.

45 Ibid., p. 80. 
cidad de otros sacrificando la propia (las verdaderas necesidades) sería una máxima contradictoria en sí misma si la convirtiéramos en ley universal. Por tanto, este deber es sólo un deber amplio; tiene espacio libre para obrar en él más o menos, sin que puedan señalarse con precisión sus límites ${ }^{46}$.

En este pasaje Kant asocia la idea de «verdaderas necesidades» a la de felicidad ${ }^{47}$. El mismo se inserta en la propuesta kantiana sobre el deber de beneficencia y arroja luz sobre el modo en que un deber moral imperfecto abre la puerta a la autonomía personal, y cómo esto incide en la felicidad y la autoautentificación.

La idea kantiana de felicidad puede resumirse como el lugar en el que quedan compendiadas todas las inclinaciones del sujeto, pese a que nunca pueda determinarse de forma precisa y fiable. La felicidad, además, es una determinación de la experiencia, y no de la razón, y como tal está causada por la contingencia y las inclinaciones y deseos de los sujetos ${ }^{48}$. Como afirma Guyer, Kant asume que «el interés en la felicidad, precisamente desde que es completamente natural para nosotros y ni debería ni puede ser extirpado, debe incorporarse en el objeto de la moralidad», es decir, «no podemos simplemente descartar el principio de la felicidad sino que debemos incorporarlo en una posición debida en nuestra comprensión completa del objeto de la moralidad» ${ }^{49}$. Con esta consideración, la paradoja antes formulada comienza a desdibujarse. Se empieza a entrever así otro modo de comprender el ser racional finito de Kant, que se asemeja más a la persona moral rawlsiana.

Budde desarrolla un interesante análisis sintáctico que le lleva a afirmar que lo que Kant pretende transmitir es que cada ser racional finito, cada persona moral, debe decidir cuáles son sus verdaderas necesidades, es decir, su concepción de la felicidad ${ }^{50}$. En palabras del propio Kant, $\ll[n]$ adie me puede obligar a ser feliz a su modo (tal como él se imagina el bienestar de otros hombres), sino que es lícito a cada uno buscar su felicidad por el camino que mejor le parezca $»^{51}$. Budde parte, pues, de la dualidad moralidad-felicidad para abrir

KANT, La metafísica de las costumbres, op. cit., Ak VI: 393.

47 Budde considera que esta identificación es clara; cfr. BUDDE, «Rawls on Kant», op. cit., p. 350.

48 KANT, Fundamentación para una metafísica de las costumbres, op. cit., Ak IV: 399, 405, 418; KANT, La metafísica de las costumbres, op. cit., Ak VI: 215.

49 GuYER, Kant on Freedom, Law, and Happiness, op. cit., pp. 212-214.

50 Ibid., pp. 349-350.

51 Kant, I., «De la Relación entre Teoría y Práctica en el Derecho Político», en Teoría y Práctica, traducción de Cortina Orts, A.; Rodríguez Aramallo, R., Tecnos, Madrid, 1986, p. 27. 
un campo caracterizado por la autonomía personal que no se reduce simplemente a la discrecionalidad de los deberes morales imperfectos. Al considerar la posibilidad de aparición de razones subjetivas para la determinación del deber de beneficencia como la interacción de dos esferas de felicidad, la propia y la de terceros, se esclarece cuál es el verdadero motivo de la «imperfección» de dicho deber: no es tanto el problema de qué tipo de beneficencia elige el sujeto, ni siquiera el de hasta qué punto debemos contribuir a la felicidad de terceros, sino cómo se consideran las «verdaderas necesidades» propias, cómo se configura la totalidad de inclinaciones que forman la felicidad. Budde es clara a este respecto: «es evidente por qué Kant dice que cada uno de nosotros por sí solo debe determinar nuestras verdaderas necesidades, porque, como Kant insiste una y otra vez, lo que nos hace felices sólo puede determinarse por la experiencia y será diferente en cada uno de nosotros $\gg^{52}$. Así pues, la autoautentificación no se da tanto en el modo de configurar la acción de beneficencia, sino en la estructura que se da a las inclinaciones propias en la configuración de un plan de vida que determine nuestro sentido de la felicidad. Aquí la interpretación de Kant está mucho más cerca de la idea de autoautentificación, puesto que implica que el sujeto, por sí mismo, debe evaluar su propia experiencia para articular sus máximas para la acción en una idea personal de felicidad.

Esta interpretación, sin embargo, no se desarrolla en dicha autora. La comprensión deductivista y formalista que hace de Kant reconoce la posibilidad de que «el test formal de la contradicción en la voluntad dé lugar a preceptos morales determinados» que otorguen contenido a los deberes morales, por lo que no requiere de la idea de felicidad a tal efecto ${ }^{53}$. Budde deslinda la posibilidad de que la felicidad se determine individualmente del hecho de que esto influya en el modo de concebir la libertad. Por esto mismo, no es necesario siquiera pensar en la capacidad de autoautentificación o la autonomía personal, puesto que no existe ningún problema de identificación de «la» conducta buena, ni es posible por tanto una elección como tal. Budde sí considera que los elementos formales destacados por Kant son suficientes para asegurar una convergencia de juicio necesario y, con ello, especificar unos modos de conducta concretos. Por esto mismo, termina por afirmar que el error de Rawls es insertar la noción «ordinaria» de libertad, entendida como libertad de elección, en el esquema kantiano. Para ella, esto no es necesario para salvar

52 BUDDE, «Rawls on Kant», op. cit., p. 350.

53 Ibid., op. cit., 350, 352. 
la indeterminación, habida cuenta de la capacidad de los rasgos formales para dotar de contenido a la ley moral ${ }^{54}$.

La pregunta que cabe plantearse es si esta interpretación se ve satisfecha con la aparición de los deberes morales imperfectos. Budde y Taylor necesitan vincular los espacios de autonomía personal a deberes morales, siquiera imperfectos, porque de no ser así no se cumpliría con la naturaleza categórica del actuar moral, partiendo de la premisa defendida de que la ley moral «proporciona» objetos a la voluntad ${ }^{55}$. Sin embargo, sus argumentos se vinculan demasiado a la idea de felicidad, cargada de elementos contingentes, como para poder sostener una posición de esa naturaleza. Si la felicidad reúne todas las inclinaciones, y está vinculada a la contingencia y la experiencia, y por lo tanto a lo fenoménico, no parece posible afirmar que dicho concepto se restrinja a deberes con uno mismo y con terceros, sino que también deberá incluir el deseo de bienes para la satisfacción de las inclinaciones propias. De este modo el campo de autoautentificación se vería ensanchado hasta aproximarse a la propuesta de Rawls.

Estos análisis abren de nuevo la paradoja de la confluencia de razones objetivas y subjetivas en toda su amplitud, una vez el vínculo a través de los deberes morales imperfectos se muestra demasiado estrecho y genera una grieta por la que la idea de la felicidad, es decir, la contingencia, la subjetividad, el ser fenoménico, cuestiona la posibilidad de las razones objetivas, categóricas.

\section{UNA LECTURA RAWLSIANA DE LA AUTONOMÍA PERSONAL EN KANT}

Sin embargo, existe una última interpretación de la obra de Kant en la que la dualidad noúmeno-fenómeno existente en las personas morales, en los seres racionales finitos, se equipara a la propuesta rawlsiana, e integra el deber moral con la autoautentificación. Esta concepción de la teoría kantiana ha sido defendida, entre otros, por Guyer y Davidson ${ }^{56}$.

Esta interpretación parte de una serie de premisas relativas a la escolástica kantiana que permiten la aparición de un espacio de autonomía personal am-

54 Ibid., pp. 352-353.

55 Vid. supra, nota 27.

56 No resulta sorprendente que en la clasificación que Taylor realiza de los estudios de la relación entre Rawls y Kant estos autores sean los que se consideran como defensores del kantismo de Rawls, junto con Darwall; cfr. TAYLOR, Reconstructing Rawls, op. cit., pp. xvii, nota 9; p. 3, nota 1. 
plio en el pensamiento kantiano. Frente a las posturas ya comentadas, eluden una comprensión de Kant que otorgue un papel casi único a la formalidad y universalidad, igual que Rawls y, en parte por eso mismo, niegan la posibilidad de entender el imperativo categórico como un elemento que «proporciona» fines o contenido a los deberes morales. La naturaleza del imperativo categórico sería entonces más bien una especie de «control negativo» de candidatos a deberes morales cuyo contenido no es deducible $a$ priori $^{57}$.

Guyer afirma que Kant, «[e]n el desarrollo completo de su teoría moral, [...] tiene que mostrar también cómo el interés en la felicidad, precisamente desde que es completamente natural para nosotros y no debe ni puede esperarse que sea extirpado, puede incorporarse al objeto de la moral en la forma del mayor de los bienes, la realización de la felicidad condicionada por el merecimiento de ser feliz» ${ }^{58}$. Al transformar la humanidad en un fin en sí mismo, esta va a ser la condición limitante de la persecución de la felicidad, precisamente como condición de la universalización posible de la felicidad ${ }^{59}$.

Esta interpretación concibe las inclinaciones de los seres racionales finitos como elementos consustanciales a su naturaleza, cuya existencia por tanto no es indicativa de maldad. La asunción de las inclinaciones del sujeto es la asunción de su propia naturaleza, que la moral no puede trascender. El problema del bien y del mal es entonces el problema de «la actitud que adoptamos hacia [las inclinaciones sensibles] como nuestra máxima fundamental $»^{60}$. Por esto mismo, las inclinaciones no se conciben como una realidad a extirpar de la acción del ser humano: «[l]a satisfacción de nuestras inclinaciones, y por lo tanto la consecución de la felicidad, es una meta natural de los seres humanos» ${ }^{61}$.

Kant, según Guyer, otorga a la moral la capacidad de determinar la motivación moral para actuar (el respeto al deber) y los rasgos formales que con-

57 Cfr. en este sentido, cfr. KRASNOFF, «How Kantian is Constructivism?», op. cit., passim. Esta idea se encuentra ya presente en la exposición de la teoría de Kant realizada por Copleston. En ella, aclara que «no se puede ni hablar de deducir reglas concretas de conducta del concepto de ley universal como tal. El concepto se usa como comprobación de la admisibilidad o inadmisibilidad de máximas, no como premisa de la cual pudieran deducirse»; cfr. COPLESTON, Historia de la filosofía, op. cit., p. 302, nota 20. Pareciera que Rawls asume esta idea; RawLs, El liberalismo político, op. cit., p. 154.

58 GuYER, Kant on Freedom, Law, and Happiness, op. cit., pp. 212-213.

59 Ibid., p. 223.

60 Ibid., p. 224.

61 Ibid., p. 226. 
dicionan todas las máximas (el principio fundamental de la moralidad), pero para que esta pueda convertirse en acción requiere la referencia a un fin que le permita determinar «hacia dónde» dirigirse ${ }^{62}$. Esta idea se refleja de forma clara en un pasaje de la Fundamentación que merece la pena reproducir extensamente:

$\mathrm{Al}$ adentrarse en un mundo inteligible por medio del pensar la razón práctica no traspasa sus confines, pero sí lo hace cuando pretende intuirse o sentirse dentro de dicho mundo inteligible. Lo primero sólo es un pensamiento negativo con respecto al mundo sensible, según el cual este último no da ninguna ley a la razón en la determinación de la voluntad, y sólo es positivo en este único punto: que esa libertad, en cuanto determinación negativa, va unida al mismo tiempo con una capacidad (positiva) e incluso con una causalidad de la razón, a la que nosotros llamamos una voluntad, capacidad para obrar de tal modo que el principio de las acciones sea conforme a la modalidad esencial de una causa racional, es decir, a la condición de que la validez universal de la máxima sea homologable con la de una ley. Pero si en ese mundo inteligible la razón práctica fuese a buscar además un objeto de la voluntad, o sea, una motivación, entonces sí traspasaría sus confines y pretendería conocer algo de lo que nada sabe. El concepto de un mundo inteligible sólo es, por tanto, un punto de vista que la razón se ve obligada a adoptar fuera de los fenómenos para pensarse a símisma como práctica [...] pero sin la más mínima pretensión de hacer algo más que pensar simplemente con arreglo a su condición formal, esto es, conforme a la universalidad de la máxima de la voluntad como ley ${ }^{63}$.

No resulta sencillo interpretar este pasaje, y menos si se pretende cohonestar con las lecturas deductivistas del imperativo categórico. Sin embargo, parece claro que plantea que lo único que un ser racional finito puede extraer legítimamente del mundo inteligible es la forma moral de sus máximas, es

62 Ibid.; cfr. KANT, I., La religión dentro de los límites de la mera razón, traducción de MARTíNEZ MarzoA, G., Alianza, Barcelona, 2001, p. 23, 6:4.

63 KaNT, Fundamentación para una metafísica de las costumbres, op. cit., Ak IV: 458, énfasis en el original; cfr., en un sentido similar, KANT, Crítica de la razón práctica, traducción de ARAMAYO, R., Alianza, Madrid, 2004, Ak V: 21-22, 27. Como afirma Guyer, los pasajes de la Crítica de la razón práctica vinculan la necesidad de restringir la ley moral a lo formal, a la indeterminación de la idea de felicidad, inconstante tanto intersubjetiva como intrasubjetivamente; cfr. GUYER, P., Kant, $2^{\mathrm{a}}$ ed., Routledge, Londres, Nueva York, 2010, pp. 211 y ss. Esta lectura refuerza las interpretaciones que se están intentando sostener. 
decir, la necesaria universalidad de las pretensiones para poder considerarlas morales. Todo lo demás, es decir, el «objeto de la voluntad», se encuentra en el mundo sensible ${ }^{64}$. En otras palabras, las inclinaciones que forman nuestra concepción de la felicidad conforman el objeto de una voluntad que, siempre que se someta a la forma universal derivada de nuestra faceta nouménica, podrá considerarse como moral.

Davidson afirma, en este mismo sentido, que en caso de que no tuviésemos inclinaciones, la propia moralidad tendría poco interés, si es que todavía le quedase alguno ${ }^{65}$. La conclusión para este autor es clara, e incide en la necesidad de que se sostenga una interpretación de Kant como la que se está desarrollando en este momento: una interpretación que pretenda excluir las inclinaciones, la realidad fenoménica de los seres racionales finitos, estaría excluyendo el motivo que da origen a la necesidad de la moral, de los imperativos categóricos ${ }^{66}$. Todo ello pese a reconocer la ambigüedad de Kant en este punto.

Kant afirma que la virtud moral es la más elevada en el sentido de que es suprema, y por lo tanto incondicionada y no subordinada, pero que no es completa, puesto que no alcanza la totalidad del bien como objeto del poder de deseo de los seres racionales finitos. Esto es así, porque para Kant, además de la virtud, el bien está compuesto por la felicidad ${ }^{67}$. No sólo esto, sino que Kant reconoce que la felicidad es una necesidad natural de los seres racionales, un imperativo que, pese a ser hipotético por dirigirse a un fin concreto, es asertórico porque dicho fin «puede presuponerse con seguridad y a priori en cualquier hombre, porque pertenece a su esencia» ${ }^{68}$.

Guyer argumenta que para Kant esto genera una relación determinada entre la persecución de la felicidad y la moral. Según el filósofo prusiano «[1] as inclinaciones naturales son, consideradas en símismas, buenas, esto es: no reprobables, y querer extirparlas no solamente es vano, sino que sería también

64 Ibid., implícito en el pasaje citado. Además, cfr. KANT, Crítica de la razón práctica, op. cit., Ak IV: 461-462, donde se refuerza esta idea.

65 Davidson, A.I., «Is Rawls a Kantian?», Pacific Philosophical Quarterly, v. 66, n. 1-2, 1985, p. 58. Aquí existiría otra similitud con Rawls, puesto que sin inclinaciones no cabría justicia, dado que esta es la que se encarga de ordenar inclinaciones contrapuestas de los sujetos de la sociedad.

66 Ibid., p. 59.

67 KANT, I., Crítica de la razón práctica, op. cit., Ak V: 110-111. Resulta ilustrativo el modo en que la relación entre la felicidad y la virtud se asemeja a cómo Rawls relaciona lo bueno y lo correcto o justo.

68 KANT, Fundamentación para una metafísica de las costumbres, op. cit., Ak IV: 415-416. 
dañino y censurable; más bien hay que domarlas, para que no se consuman las unas por las otras, sino que puedan ser llevadas a concordar en un todo llamado felicidad $»^{69}$. En este sentido, «la diferencia -esto es: si el hombre es bueno o malo- tiene que residir no en la diferencia de los motivos que él acoge en su máxima (no en la materia de su máxima) sino en la subordinación (la forma de la máxima): de cuál de los dos motivos hace el hombre la condición del otro» ${ }^{70}$. Esto implica, según Guyer, que «la realización de las inclinaciones humanas puede asumirse como una parte de lo que es bueno para los seres humanos. Realizamos nuestra posibilidad radical para el mal sólo si 'invertimos el orden moral de [nuestros] incentivos al incorporarlos en [nuestras] máximas' $\gg^{71}$. Por lo tanto, el rasgo esencial de la moral kantiana sería la exigencia de prioridad de la moral sobre la felicidad, o en términos rawlsianos, de lo recto (justo) sobre lo bueno ${ }^{72}$. Esta idea, como resulta evidente, aproxima a Kant a Rawls al situar un elemento común en sus obras como esencial en sus pensamientos. En Themes in Kant's Moral Philosophy, Rawls hace una interpretación similar de la idea de la libertad negativa y su relación con la ley moral en el pensamiento de Kant, al afirmar que «sabemos por adelantado, independientemente de cuáles sean nuestros deseos naturales, que la ley moral impone ciertos fines, así como restricciones a los medios, y que estos requisitos son siempre válidos para nosotros ${ }^{73}$.

Esta interpretación de Kant consigue asegurar la libertad entendida como capacidad de cada individuo para perseguir su propia formulación de la felicidad, la autonomía personal. Siguiendo su propia filosofía, «[n]adie me puede obligar a ser feliz a su modo (tal como él se imagina el bienestar de otros hombres), sino que es lícito a cada uno buscar su felicidad por el camino que mejor le parezca, siempre y cuando no cause perjuicio a la libertad de los demás para pretender un fin semejante, libertad que puede coexistir con la libertad de todos según una posible ley universal (esto es, coexistir con ese derecho del otro)» ${ }^{74}$. Este pasaje resuena en la teoría de Rawls, en la que la justicia se concibe como la salvaguarda de la autonomía entendi-

69 KANT, La religión dentro de los límites de la mera razón, op. cit., pp. 78-79, 6:58.

70 Ibid., p. 56, 6:36. Los dos motivos son la ley moral y los motivos de la sensibilidad. En un sentido similar, KANT, Fundamentación para una metafísica de las costumbres, op. cit., Ak. IV 396.

71 GuYer, Kant on Freedom, Law, and Happiness, op. cit., p. 224.

72 Cfr. por ejemplo, RawLs, «Kantian Constructivism in Moral Theory», pp. 317 y ss.

73 Rawls, J., «Themes in Kant's Moral Philosophy», Collected Papers, op. cit., p. 525.

74 KANT, «De la Relación entre Teoría y Práctica en el Derecho Político», op. cit., p. 27. 
da como capacidad de autoautentificar las concepciones de la felicidad en cada individuo. Ello permitiría afirmar que las máximas de la acción de cada sujeto pueden ser diferentes cumpliendo la ley moral, puesto que esta no sería suficiente para determinar, en seres racionales finitos, el objeto de sus máximas $^{75}$.

Guyer desarrolla esta lectura de la personalidad moral kantiana en su obra sobre Kant, afirmando que el rasgo esencial de los seres racionales o de la humanidad (términos que considera intercambiables), es la capacidad de «fijar y perseguir nuestros fines particulares de un modo que sea consistente con la preservación y promoción de nuestra capacidad general para fijarnos fines $\gg^{76}$. Cabe destacar que autores como Doppelt han resaltado una conexión en este sentido al hablar del «Ideal kantiano de la personalidad de Rawls», caracterizado además por «el sentido del bien como la autodeterminación normativa» ${ }^{77}$.

De nuevo, Rawls sostiene una lectura similar cuando afirma que no se debe interpretar la suficiencia de la ley moral para determinar la voluntad de forma demasiado fuerte. $\mathrm{Al}$ contrario,

la ley moral especifica un ámbito dentro del que los fines permisibles deben estar incluidos, y también limita los medios que pueden usarse en su persecución, y esto está a medio camino de hacer a la ley moral suficiente por sí misma para determinar la voluntad. (Por supuesto los deseos particulares determinan qué fines permisibles es racional que persigamos, y también de-

75 Guyer desarrolla esta lectura de la personalidad moral kantiana en su obra sobre Kant, afirmando que el rasgo esencial de los seres racionales o de la humanidad (términos que considera intercambiables), es la capacidad de «fijar y perseguir nuestros fines particulares de un modo que sea consistente con la preservación y promoción de nuestra capacidad general para fijarnos fines»; cfr. GUYER, Kant, op. cit., p. 215. En general, resulta ilustrativo todo el capítulo 5, «Laws of freedom. The foundations of Kant's moral philosophy». Cabe destacar que autores como Doppelt han resaltado una conexión en este sentido al hablar del «Ideal kantiano de la personalidad de Rawls», caracterizado además por «el sentido del bien como la autodeterminación normativa», cfr. Doppelt, G., «Beyond Liberalism and Communitarianism: Towards a Critical Theory of Social Justice», Philosophy \& Social Criticism, v. 14, n. 3-4, 1988, pp. 277 y ss; es decir, por un «igual valor de la capacidad de todas las personas para la autodeterminción», cfr. DOPPELT, «Rawls' Kantian Ideal and the Viability of Modern Liberalism», op. cit., p. 439.

76 GUYER, Kant, op. cit., p. 215. En general, resulta ilustrativo todo el capítulo 5, «Laws of freedom. The foundations of Kant's moral philosophy».

77 Doppelt, «Beyond Liberalism and Communitarianism», op. cit., pp. 277 y ss. Esto es lo mismo que reconocer un «igual valor de la capacidad de todas las personas para la autodeterminción», cfr. Doppelt, «Rawls' Kantian Ideal and the Viability of Modern Liberalism», Inquiry, v. 31, n. 4, 1988, p. 439. 
terminan, dentro de los límites permitidos, cómo es racional que los persigamos. Esta libertad de acción [leeway] la considero compatible con las intenciones de Kant $)^{78}$.

Esta interpretación que Rawls hace de las obras de Kant insiste en una concepción de la ley moral como medio de «control negativo», en el que el objeto de la voluntad no se deriva deductivamente de ella, y abre un espacio de influencia de la idea de felicidad de cada individuo en la que lo fenoménico se inserta, aunque siempre subordinado, en la moral.

Davidson, por su parte, defiende de forma explícita el hecho de que Rawls, pese a renunciar al idealismo trascendental kantiano, «retiene el sentido de algunas tendencias de esta metafísica $\gg^{79}$. Este autor afirma que es necesario evitar una lectura maniquea del binomio kantiano espontaneidad-receptividad, de razón e inclinación. Esto puede hacerse concentrándose, como hace Kant, en la noción de prioridad, que para Davidson es un elemento esencial y reconocido del pensamiento kantiano. Esta prioridad implicaría que «el concepto del bien y el mal debe ser definido después de y por medio de la ley» ${ }^{80}$. Esta lectura parte de entender que Kant, como afirma Guyer, no pretende extirpar la felicidad de la praxis humana, sino determinar su debido lugar, subordinado a la moral. Davidson afirma que Kant lo que hace es combatir la tendencia del utilitarismo a «homogeneizar» los intereses prácticos, evitando que la maximización de la felicidad se convierta en «el único motivo de la determinación de la voluntad ${ }^{81}$; impidiendo que este sea «el único» motivo, pero permitiendo que sea uno de los motivos, siempre que ocupe el lugar que le corresponde.

Por eso mismo Davidson defiende la heterogeneidad de los deseos, derivada de la heterogeneidad del sujeto, su dualidad fenómeno-noúmeno, y propone la subordinación como rasgo esencial de la moral kantiana, y por influencia de esta también de la teoría de la justicia rawlsiana.

En este sentido, la facultad de deseo «patológicamente determinable»o «inferior», en la moral kantiana, es «subordinada a» la facultad «superior» ${ }^{82}$, en lugar de considerarse como un elemento a extirpar. Davidson entiende que esta

\footnotetext{
78 RawLs, J., «Themes in Kant's Moral Philosophy», op. cit., p. 525.

79 DAVIDSON, «Is Rawls a Kantian?», op. cit., p. 49.

80 Ibid., p. 51; KANT, Crítica de la razón práctica, op. cit., Ak, V: 23-63, 65.

81 DAVIDSON, «Is Rawls a Kantian?», op. cit., p. 54.

82 KANT, Crítica de la razón práctica, op. cit., Ak V: 23-25, sobre la definición de las facultades «superior»e «inferior».
} 
relación entre elementos es la que permite distinguir al ser racional finito, y que lo que nos distingue de los animales no es la posesión de la razón, sino cómo la empleamos, subordinándola a la moral pero dirigiéndola a la consecución de nuestros fines. Para defender esta idea, Davidson recurre a una larga cita de Kant:

El ser humano es un ente menesteroso [bedürftige ${ }^{83}$ en cuanto perteneciente al mundo sensible y, en esa medida, su razón tiene un cometido indeclinable con respecto a la sensibilidad, cual es el velar por sus intereses otorgándole máximas prácticas con vistas a la felicidad en esta vida e igualmente para una posible vida futura. Sin embargo, no es tan enteramente animal como para resultarle indiferente cuanto le diga la razón por sí misma y utilizar ésta simplemente como un instrumento para satisfacer su menesterosidad en cuanto ser sensible. Pues en absoluto elevaría su valor por encima de la mera animalidad el que posea una razón, si ésta sólo debe servirle para lo mismo que lleva a cabo el instinto entre los animales; la razón supondría entonces tan sólo una peculiar manera de la cual se habría servido la naturaleza para equiparar al ser humano en orden a un fin similar al que ha determinado para los animales, sin destinarle a él mismo hacia un fin más alto. Desde luego, conforme a lo dispuesto con él por la naturaleza, el ser humano necesita la razón para tener presente a cada momento su provecho y su perjuicio, pero la tiene además para una misión más alta, consistente no sólo en reflexionar también acerca de lo que sea bueno o malo en sí, y sobre lo cual únicamente puede juzgar la razón pura al margen de cualquier interés sensible, sino asimismo para distinguir por completo este juicio respecto de aquel otro y convertirlo en la suprema condición del mismo ${ }^{84}$.

Este autor reconoce entonces la identidad entre la idea de la relación de subordinación entre los dos tipos de facultades del deseo y la subordinación rawlsiana de lo racional a lo razonable ${ }^{85}$. El propio Rawls plantea una lectura similar de Kant al referirse a la relación entre la razón práctica pura y la razón práctica empírica ${ }^{86}$.

83 Este término puede considerarse como sinónimo de «necesitado». En la versión inglesa de Cambridge University Press se traduce la frase del siguiente modo: «The buman being is a being with needs»; cfr. KanT, I., Critique of Practical Reason, traducción de Gregor, M., Cambridge University Press, Cambridge, 2015.

84 DaVIDSON, «Is Rawls a Kantian?», op. cit., p. 57; KanT, Crítica de la razón práctica, op. cit., Ak V: 61-62; en un sentido similar, KANT, Fundamentación para una metafísica de las costumbres, op. cit., Ak IV: 426-428.

85 DAVIDSON, «Is Rawls a Kantian?», op. cit., pp. 56 y ss.

86 Rawls, J., «Themes in Kant's Moral Philosophy», op. cit., pp. 502 y ss. 
Este modo de comprender la relación entre moral y bien o felicidad abre un campo mayor para la «autonomía personal» en la obra de Kant, que permite identificarla con la capacidad de autodeterminar la propia comprensión de la felicidad de uno mismo, es decir, la legitimidad de la autoautentificación del modo de ordenar las inclinaciones que las personas morales reciben del mundo sensible como seres fenoménicos. En este sentido, se actúa moralmente si se persigue la felicidad, determinada por inclinaciones recibidas del mundo sensible, siempre y cuando esta se subordine a las exigencias formales y los motivos del deber que sí se pueden derivar a priori de la naturaleza del ser racional finito.

Evidentemente, una concepción de este estilo hace entrar la contingencia en la determinación de los planes de vida y la felicidad de los individuos, y en cierto modo afecta al contenido de las acciones morales, aunque no a su forma ni a la motivación de las mismas. Sin embargo, de las citas de Kant que se han ido exponiendo puede extraerse una comprensión de su teoría en este sentido. Como se ha señalado, Rawls también reconoce una posibilidad idéntica en diferentes partes de su obra, en las que, siguiendo esta idea de subordinación, la contingencia en la determinación del plan de vida se convierte en irrelevante desde el punto de vista de la justicia en el momento en que no se vulneran los principios de la justicia. Por ejemplo, en $A$ Theory of fustice, se afirma que «[n]o hay objeción alguna a hacer al ajuste de los proyectos racionales a estas contingencias [las facultades, aspiraciones, circunstancias especiales, la posición social y las dotes naturales], porque los principios de la justicia han sido elegidos ya y determinan el contenido de estos proyectos, los objetivos que fomentan y los medios de que se valen ${ }^{87}$.

\section{CONCLUSIÓN}

Pese a que algunas de las interpretaciones de Kant puedan ser objeto de fuertes disputas, parece que del recorrido realizado se puede extraer una mejor comprensión de cómo entiende Rawls la personalidad moral, y de cuáles son las conexiones que reclama con la tradición kantiana; conexiones que, por otro lado, están refrendadas con algunas de las comprensiones que autores destacados han hecho de la obra de Kant.

87 RaWLs, Teoría de la justicia, op. cit., pp. 407, 511. 
Es evidente que no se puede hablar de similitud entre las ideas de Rawls y las de Kant si se evalúa la obra del filósofo de Königsberg desde la perspectiva expuesta en el segundo apartado, en las que la parte fenoménica aparece cercenada. Resulta difícil entender cómo un modelo de esta naturaleza puede aplicarse a seres humanos que se ven influidos por la causalidad fenoménica, e incluso puede afirmarse que tal lectura obvia todo el estudio de Kant sobre la interacción entre felicidad y moral, y así también la distinción entre la forma y el «objeto» de la voluntad, de las máximas que se deben considerar o no acordes a la moral.

Sin embargo, la interpretación rawlsiana de Kant hunde sus raíces en un modo de comprender la filosofía moral del filósofo prusiano que justifica las analogías expuestas por Rawls. En primer lugar, la concepción kantiana de la humanidad como complejo formado por razón (práctica, es decir, moral) e inclinación guarda cierta similitud, que se puede considerar claramente como analogía, con la dualidad racionalidad/razonabilidad de Rawls. En Kant, los seres racionales finitos se ven guiados por motivos tanto de la ley moral como de la sensibilidad. El motivo moral requiere tanto la universabilidad de la máxima, su conformidad formal, como la actuación por el deber. El motivo de la sensibilidad otorga la materialización de la voluntad en un fin concreto. Por su parte, en Rawls, la racionalidad elige el plan de vida del individuo, y a través de dicha elección lo convierte en su propio bien. Sin embargo, la razonabilidad establece los límites que dicha elección no puede trascender; límites que coinciden con los principios de la justicia.

Por ello, en segundo lugar, tanto Rawls como Kant reconocen una esfera de autonomía personal en la que el individuo configura su propia concepción de la felicidad o de su plan de vida. En Kant, siempre y cuando se cumpla con el imperativo categórico y su mandato de universabilidad de las máximas, así como con la exigencia de obrar por el deber ${ }^{88}$, será lícito configurar una idea personal de la felicidad y perseguirla. Esta configuración de la idea propia de felicidad es una empresa que se le encomienda al propio individuo.

88 El propio Kant se cuestiona que en seres racionales finitos, es decir, en seres humanos, sea posible asegurar la existencia inmaculada de una obra fundada simplemente en el deber. En cierto modo, se reconoce la interacción de inclinaciones sensibles y la motivación moral; KANT, Fundamentación para una metafísica de las costumbres, op. cit., Ak IV 407. Por ello, la universabilidad como exigencia de la ley moral es la que cobra un protagonismo más elevado como restricción de las concepciones individuales de la felicidad. 
La principal exigencia de la ley moral o de la justicia es entonces que la idea personal de felicidad o los motivos de la sensibilidad se sometan a los motivos de la moral, en términos kantianos, o que la persecución de planes de vida se halle limitada por las exigencias de la razonabilidad o la justicia, en términos rawlsianos ${ }^{89}$.

\section{BiBLIOGRAFÍA}

Buchanan, A., Marx and fustice: The Radical Critique of Liberalism, Methuen, Londres, 1982.

BUDDE, K., «Rawls on Kant: Is Rawls a Kantian or Kant a Rawlsian?», European fournal of Political Theory, v. 6, n. 3 (2007), pp. 339-358.

Copleston, F., Historia de la filosofía, vol. 6: «De Wolff a Kant» (Traducción de J.M. García de la Mora), Ariel, Barcelona, 1984. (Original inglés, A History of Philosophy, vol. VI: Wolff to Kant, Search Press, Londres, 1960).

DARWALL, S.L., «Is There a Kantian foundation for Rawlsian Justice?», en G. Blocker y E. Smith (eds.), Fohn Rawls' Theory of Social fustice. An Introduction, Ohio University Press, Athens, 1980, pp. 311-345.

Davidson, A.I., «Is Rawls a Kantian?», Pacific Philosophical Quarterly, v. 66, n. 1-2 (1985), pp. 48-77.

DoppeLt, G., «Beyond Liberalism and Communitarianism: Towards a Critical Theory of Social Justice», Philosophy \& Social Criticism, v. 14, n. 3-4 (1988), pp. 271-292.

- «Rawls' Kantian Ideal and the Viability of Modern Liberalism», Inquiry, v. 31, n. 4 (1988), pp. 413-449.

- «Is Rawls's Kantian Liberalism Coherent and Defensible?», Ethics, v. 99, n. 4 (1989), pp. 815-851.

Guyer, P., Kant on Freedom, Law, and Happiness, Cambridge University Press, Cambridge, 2000.

- Kant, $2^{\mathrm{a}}$ ed., Routledge, Londres, Nueva York, 2010.

Herman, B., «Mutual Aid and Respect for Persons», Ethics, v. 94, n. 4 (1984), pp. 577602.

HöfFE, O., «Is Rawls' Theory of Justice Really Kantian?», Ratio Bristol, v. 26, n. 2 (1984), pp. 103-124.

89 Sandel afirma que el rasgo esencial de lo que él denomina «liberalismo deontológico» se encuentra precisamente en la prioridad de lo justo sobre lo bueno, un rasgo que asocia a Rawls y que considera originario de las ideas de Kant; cfr. SANDEL, Liberalism and the Limits of fustice, op. cit., p. 1. El propio Rawls considera este rasgo como un «rasgo central de nuestra concepción», RAWLs, Teoría de la justicia, op. cit., p. 42. Además, también lo asocia a la tradición kantiana; cfr., ibid., p. 42, nota 16; RAWLS, «Kantian Constructivism in Moral Theory», op. cit., p. 319. Para un análisis de la prioridad de lo justo sobre lo bueno en la conexión entre Rawls y Kant, cfr. TAYLOR, Reconstructing Rawls, op. cit., pp. 116 y ss. 
KANT, I., «De la Relación entre Teoría y Práctica en el Derecho Político», en Teoría y Práctica (Traducción de A. Cortina Orts y R. Rodríguez Aramallo), Tecnos, Madrid, 1986, pp. 25-50.

- La metafísica de las costumbres (Traducción de A. Cortina Orts y J. Conill Sancho), Tecnos, Madrid, 1989.

- La religión dentro de los límites de la mera razón (Traducción de G. Martínez Marzoa), Alianza, Barcelona, 2001.

- Fundamentación para una metafísica de las costumbres (Traducción de R. Aramayo), Alianza, Madrid, 2002.

- Crítica de la razón práctica (Traducción de R. Aramayo), Alianza, Madrid, 2004.

- Critique of Practical Reason (Traducción de M. Gregor), Cambridge University Press, Cambridge, 2015.

KraSNOFF, L., «How Kantian is Constructivism?», Kant-Studien, v. 90, n. 4 (1999) pp. 385-409.

- «Kantian Constructivism», en J. Mandle y D.A. Reidy (eds.), A Companion to Rawls, Wiley Blackwell, Malden, 2014, pp. 73-87.

Levine, A., «Rawls' Kantianism», Social Theory and Practice, v. 3, n. 1 (1974), pp. 47-63.

RaWls, J., «A Kantian Conception of Equality», Cambridge Review, v. 96 (1975), pp. 536-555. Reproducido en Freeman, S. (ed.), Collected Papers, Harvard University Press, Cambridge, 1999, pp. 254-266.

- «Kantian Constructivism in Moral Theory», The fournal of Philosophy, v. 77, n. 9 (1980), pp. 515-572. Reproducido en Freeman, S. (ed.), Collected Papers, Harvard University Press, Cambridge, 1999, pp. 303-358.

- «Justice as Fairness: Political not Metaphysical», Philosophy and Public Affairs, v. 14, n. 3 (1985), pp. 223-252. Reproducido en Freeman, S. (ed.), Collected Papers, Harvard University Press, Cambridge, 1999, pp. 388-414.

- «Themes in Kant's Moral Philosophy», en Foster, E. (ed.), Kant's Transcendental Deductions: The «Three Critiques» and the «Opus Postumum», Stanford University Press, Palo Alto, 1989, pp. 81-113. Reproducido en Freeman, S. (ed.), Collected Papers, Harvard University Press, Cambridge, 1999, pp. 497-528.

- Teoría de la justicia (Traducción de M.D. González), $2^{\mathrm{a}}$ ed., Fondo de Cultura Económica, México, 1995. (Originales en inglés: $A$ Theory of fustice, $1^{\mathrm{a}}$ ed., Harvard University Press, Cambridge, 1971. A Theory of fustice, 2a ed., Harvard University Press, Cambridge, 1999).

- El liberalismo político (Traducción de A. Domènech), Crítica, Barcelona, 1996. (Original inglés, Political Liberalism, Columbia University Press, Nueva York, 1993).

RAZ, J., The Morality of Freedom, Clarendon Press, Oxford, 1986.

SANDEL, M.J., Liberalism and the Limits of Fustice, $2^{\mathrm{a}}$ ed., Cambridge University Press, Cambridge, 1998.

TAYLOR, R.S., Reconstructing Rawls. The Kantian Foundations of Justice as Fairness, Pennsylvania State Press, Pennsylvania, 2011. 
0000 